\title{
The Simulation and Research of T Source Inverter Based on Matlab/Simulink and Modified SVPWM Control without Sector Judgment
}

\author{
Yang Wang, Hong Zhu, Wenqing Ling, Chenlu Dong, Panpan Yang \\ College of Electrical and Information Engineering, Anhui University of Science and Technology, \\ Huainan 232001, China
}

Keywords: T source inverter, SVPWM, sector, harmonic content.

\begin{abstract}
The growing demand for energy to promote the research in the field of power transformation, in order to improve the efficiency of the power converter further, many different circuit topologies and control strategies were proposed. In this paper, one of improved topologies is proposed which called T-source inverter, its special T source network can reduce the use of passive devices, adopting the modified SVPWM control, without complicated coordinate transformation and the sector judgment ,experiment of simulation carried out under the Matlab/Simulink.
\end{abstract}

\section{Introduction}

The z-source inverter designed by F ,Z ,Peng in the year 2002 overcomes the difficulties in conventional voltage and current source inverters. It is done to complete the step-up/step-down by adjusting the impedance network buck and duty. The power conversion stages also get reduced resulting in improved efficiency of the system in energy conversion process.

Because of the $\mathrm{Z}$ source inverter circuit in a single-stage topology without boosting voltage, it can use the DC side voltage better. Directly connected voltage source and inverter using consists of a pair of capacitance and inductance of the $\mathrm{Z}$ source network, it will be through the zero state into the switching states of the inverter in order to improve the output voltage of inverter by controlling shoot-through duty cycle, and inverter output AC voltage range will be wider, then the voltage AC voltage peak value is even higher than DC side. To improve the performance of the inverter further different topologies of Z-source inverter has been proposed by different possible combination of arrangement of passive components and a variety of control strategies in recent years.

As to improve inverter topology on the Z-source inverter, the inverter is called $T$ source inverter instead of Z-source inverter.. This article describes the $\mathrm{T}$ source inverter and $\mathrm{Z}$ source inverter works and adoption of improved technology to control T source SVPWM inverter and builds T source inverter SVPWM simulation model based on improved control in Matlab/simulink environment with the Z-source inverter for comparison.

\section{The Principle of two inverters}

The $\mathrm{T}$ source inverters are mainly classified as the Voltage $\mathrm{T}$ Source Inverters (VSI) and the T Current Source Inverters (CSI). This article mainly analysis the Voltage T source inverter. As is shown in figure 1:

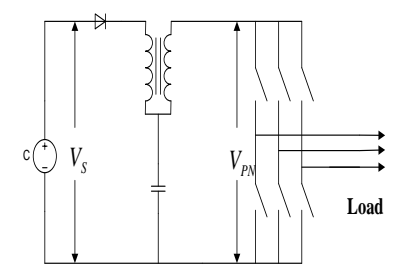

Figure 1.T source inverter circuit topology 
By changing the duty ratios for lifting pressure $\mathrm{T}$ source inverter can realize single stage inverter .Similar to the $\mathrm{Z}$ source inverter, it adopts unique impedance network to connected together dc voltage source inverter and circuit .T network is controlled by a belt of small leakage inductance and capacitance of the pulse transformer .Compared with $\mathrm{Z}$ source network, $\mathrm{T}$ source network reduces the use of passive components and the power transformation stage, of course including the harmonic content of output voltage .The $\mathrm{Z}$ source network is shown in figure 2 :

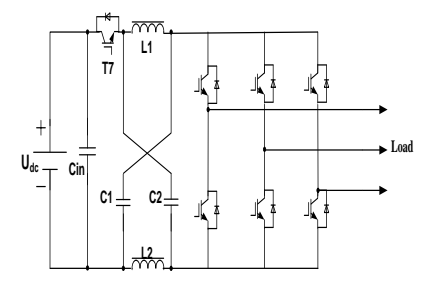

Figure 2.Z source inverter circuit topology

As the design of impedance network allows the inverter to run under direct state, therefore, the energy transfer from the inductance capacitance so as to improve the performance of the inverter booster .It dose not need to set the dead zone time so as to reduce harmonic and enhance the transient response of system the output waveform. That is to say, the lower LC filter can be an ideal sinusoidal output voltage and the duty cycle is controlled by controlling the inverter through the up / down . Adopting a source inverter can reduce the surge current and harmonic, $\mathrm{T}$ source inverter has two operating status: a shoot-through state and a non- shoot-through state.

\section{The shoot-through state}

In the shoot-through state, the diode is reverse biased, the $\mathrm{T}$ source and $\mathrm{Z}$ source equivalent circuit is shown in figure 3 .
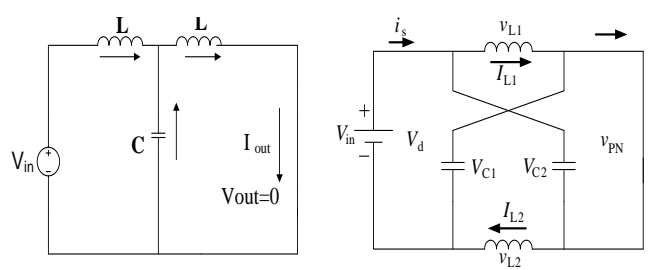

Figure 3.T source and Z source inverter shoot-through state

\section{The non-shoot-through state}

Figure 4 shows in non-shoot-through running state, the T source inverter is the same as the state of traditional inverter operation, including the diode conduction and the two equal inductance current because of coupled inductance.

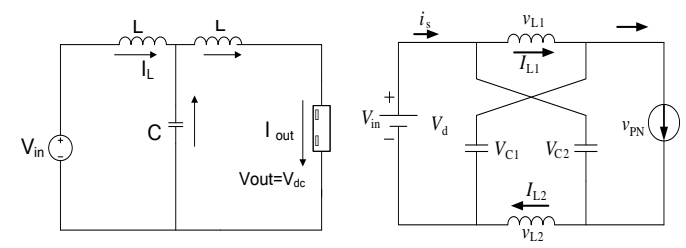

Figure 4.T source and Z source inverter non-shoot-through state

$\mathrm{Z}$ source inverter in non-shoot-through running state and $\mathrm{Z}$ source inverter alternates its shoot-through and non-shoot-through status to boost voltage. As shown below.

\section{The design of $T$ source inverter}

$\mathrm{T}$ source inverter is based on the minimum input voltage inverter to calculate $\mathrm{T}$ source network components value and the average inductor current, 


$$
I_{L}=\frac{P}{V_{d c}}
$$

There is a maximum ripple current in the maximum shoot running state and it will select $60 \%$ of ripple current peak to design $\mathrm{T}$ source inverter. The ripple current is $\Delta I_{L}$ The maximum current through the inductor is $I_{L \max }$,

$$
\begin{aligned}
& I_{L \text { min }}=I_{L}-\Delta I_{L} \\
& I_{L \text { max }}=I_{L}+\Delta I_{L} \\
& \Delta I_{L}=0.5\left(I_{L \text { max }}-I_{L \text { min }}\right)
\end{aligned}
$$

The boosting factor of the input voltage:

$$
K=\frac{1}{1-2 D_{T}}
$$

The shoot-through duty cycle is $\mathrm{D}_{\mathrm{T}}$, A peak voltage of phase is $V_{a-p}$,

$$
V_{a-p}=M \frac{V_{p-d c}}{2}=M K \frac{V_{i n}}{2}
$$

Where, $\mathrm{M}$ is modulation factor, $\mathrm{K}$ is the boost factor and $\mathrm{K}>1, \mathrm{~V}_{\mathrm{p} \text {-dc }}$ is the $\mathrm{DC}$ side of the peak voltage, calculating Z-source inverter required inductance:

$$
L=\frac{T_{0} * V_{C}}{\Delta I_{L}}
$$

$\mathrm{T}_{0}$ is the shoot-through time of each switching cycle, $\mathrm{Tz}$ is the switching period, calculating the required capacitance of the $\mathrm{T}$ inverter source is given by.

$$
C=\frac{I_{L} * T_{Z}}{\Delta V_{C}}
$$

Where, $\Delta V_{C}$ is the ripple voltage, $\mathrm{V}_{\mathrm{C}}$ is the capacitor voltage.

\section{Modified SVPWM control}

Three-phase inverter SVPWM control technology is often used because of its high DC voltage utilization, generating less harmonic distortion. In this paper, the modified SVPWM control is added through state control on the basis of traditional SVPWM voltage source inverter, but not to affect its active state. The reference voltage $V_{\text {ref }}$ is synthesized by two voltage vectors $V_{i}$ and $V_{i+1}$.

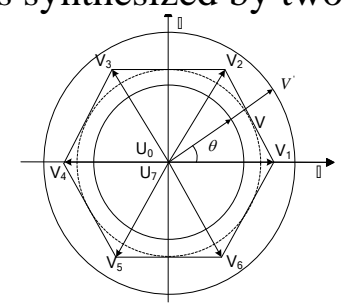

Figure 5.SVPWM vector and sectors

For example, in sector 1, inserted through the effective time does not affect the vector space vector. As shown in figure 6 is modified SVPWM vector diagram, space vector reference voltage as shown in type (1).

$$
V_{\text {ref }}=V_{i} T_{1}+V_{i+1} T_{2}
$$

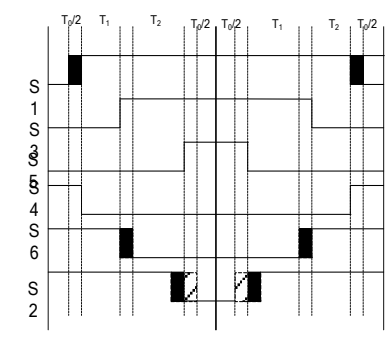

Figure 6.The SVPWM of sector 1 
As shown in formula (2) is Space vector modulation technology of modulation index.

$$
M=\frac{V_{r e f}}{(2 / 3) V_{d c}}
$$

T source inverter DC voltage rises is added through time $T$ by the switching times $T_{1}, T_{2}$ and $T_{0}$ to generate the output sinusoidal AC voltage.

$$
\begin{aligned}
& V_{a-p}=M \frac{V_{p-d c}}{2}=M K \frac{V_{i n}}{2} \\
& K=\frac{T_{z}}{T_{b}-T_{a}}=\frac{1}{1-2 \frac{T_{a}}{T_{z}}}=\frac{1}{1-2 D_{z}}
\end{aligned}
$$

$\mathrm{T}_{\mathrm{z}}=\mathrm{T}_{a}+\mathrm{T}_{b}, \mathrm{~T}_{z}$ is the switching period, $\mathrm{T}_{a}$ and $\mathrm{T}_{b}$ is the total time about the shoot-through state time and the non-shoot-through state time $\mathrm{M}$ is the modulation factor, $\mathrm{K}$ is a step factor, and $\mathrm{V}_{p \text {-dc }}$ is the DC voltage peaks.

When the switching bridge arm are simultaneously turned on In a state of occurring shoot-through, the total duration of $\mathrm{T}_{a}$ is given by, $\mathrm{T}_{a}=3 \mathrm{~T}$ and $\mathrm{DC}$ voltage has rose in time. In a switching cycle $\mathrm{T}_{z}$, by adjusting through time can it control the size of DC side voltage and the size of the inverter output voltage without changing zero vector $\mathrm{V}_{0}, \mathrm{~V}_{7} \mathrm{~T}$ and a non-zero vector $\mathrm{V}_{1} \sim \mathrm{V}_{6}$.

\section{Simulation}

In establishment of simulation by using MATLAB / SIMULINK, the DC source voltage is $100 \mathrm{~V}$, and T source inverter capacity is 360nf, T source inverter inductor is $0.2 \mathrm{mH}$, the transformer turn ratio is $1: 1$ and the resistance of the load is $150 \Omega$. Shown in Figure 9 is T source inverter simulation based on SVPWM control.

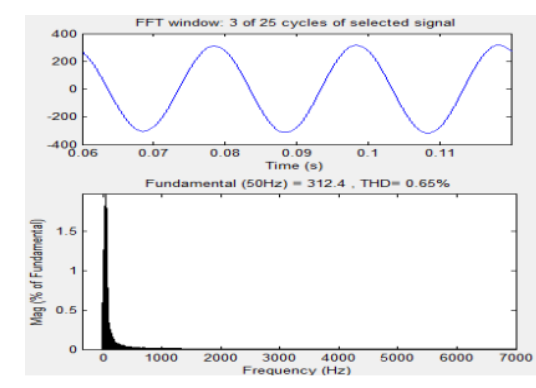

Figure 7.FFT analysis of the voltage source inverter output $\mathrm{T}$ A phase filtered

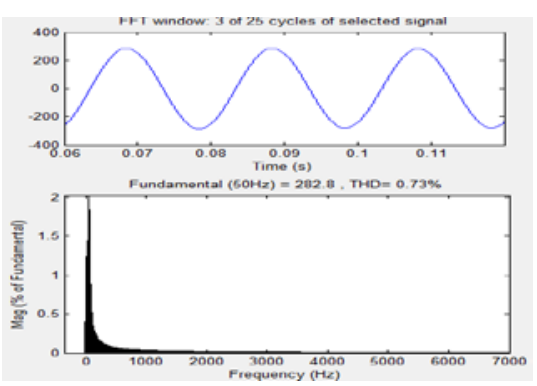

Figure 8.FFT analysis of the voltage source inverter output Z A phase filtered

As shown in the figure 7 displays the analysis of voltage FFT after the output of T source inverter filter A phase filter and figure 8 shows the analysis of $\mathrm{T}$ source inverter filter output voltage relative to the filtered FFT.

That can be seen less $\mathrm{T}$ source inverter output harmonic content and in the same control technology, the step-up ratio of T source inverter voltage boost higher than Z-source inverter. 


\section{Conclusion}

This paper analyzes the T source inverter in the performance of the improved SVPWM control. By comparing the harmonic content of the output voltage, the conclusion about using fewer passive components can reduce the harmonic content of the output voltage is Verified and given by and under the same control technology, the voltage of T source inverter boost higher than the Z-source inverter.

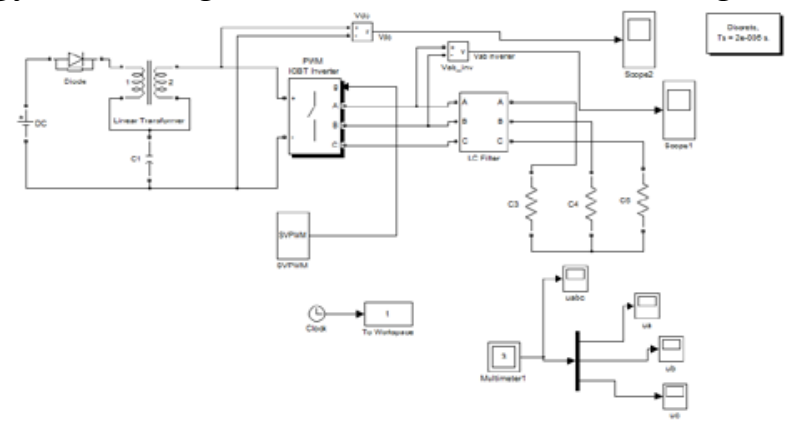

Figure 9.T source inverter controlled by SVPWM

\section{Reference}

[1] RUI Qi-hua, DU Shao-wu, JIANG Wei-dong. Current Regulation for Three-phrased Grid-connected Inverter Based on SVPWM Control[J]. Power Electronics, 2010, (6): 4-5.

[2] Marek Adamowicsz, Natalia Strzeleckal and Wieslaw Bury "New type T-source inverter" In proceeding on international conference of compatibility in power Electronics-2009 pp-191-195.

[3] Sivaraman P and Nirmal kumar A, "Analysis and implementation of a novel T-source inverter for high voltage gain application” International Review of Modeling and Simulation vol.5 pp 818-825 April 2012 ISSN 1974-9821.

[4] Sivaraman and A. Nirmalkumar, "Analysis of T-Source Inverter with Various PWM Schemes”, European Journal of Scientific Research ISSN 1450-216, Vol.71 No.2, pp. 203-213, 2012

[5] J. Rabkowski, "Improvement of Z-source inverter properties' using advanced PWM methods,” in Proc. the 13th Eur. Conf. Power Electron. Appl., Sep. 8-10, 2009, pp: 1-9 